\title{
Synchrotron radiation Fourier-transform infrared and Raman microspectroscopy study showing an increased frequency of creatine inclusions in the rat hippocampal formation following pilocarpine-induced seizures
}

\author{
J. Dulinska $\cdot$ Z. Setkowicz $\cdot$ K. Janeczko $\cdot$ C. Sandt • \\ P. Dumas $\cdot$ L. Uram $•$ K. Gzielo-Jurek • J. Chwiej
}

Received: 28 July 2011 /Revised: 15 September 2011 / Accepted: 9 October 2011 / Published online: 29 October 2011

(C) The Author(s) 2011. This article is published with open access at Springerlink.com

\begin{abstract}
In the present work, synchrotron radiation Fourier-transform infrared (SRFTIR) and Raman microspectroscopies were used to evaluate a possible role of creatine in the pathogenesis and progress of pilocarpineevoked seizures and seizure-induced neurodegenerative changes in the rat hippocampal tissue. The main goal of this study was to identify creatine deposits within the examined brain area, to analyze their frequency in epileptic animals and naive controls and to examine correlations between the number of inclusions in the hippocampal formation of epileptic rats and the quantitative parameters describing animal behavior during 6-h observation period after pilocarpine injection. The presence of creatine in the brain tissue was confirmed based on the vibrational bands specific for this compound in the infrared and Raman spectra. These were the bands occurring at the wave-
\end{abstract}

Published in the special issue Analytical and Bioanalytical Science in Poland with guest editor Marek Biziuk.

Electronic supplementary material The online version of this article (doi:10.1007/s00216-011-5488-z) contains supplementary material, which is available to authorized users.

J. Dulinska J. Chwiej $(\bowtie)$

AGH University of Science and Technology,

Faculty of Physics and Applied Computer Science,

30-059 Krakow, Poland

e-mail: jchwiej@novell.ftj.agh.edu.pl

Z. Setkowicz $\cdot$ K. Janeczko $\cdot$ L. Uram $\cdot$ K. Gzielo-Jurek Jagiellonian University, Faculty of Biology and Earth Sciences, Institute of Zoology,

31-007 Krakow, Poland

C. Sandt $\cdot$ P. Dumas

SOLEIL,

St Aubin, BP 48, 91192 Gif-sur-Yvette Cedex, France numbers around 2800,1621, 1398, and $1304 \mathrm{~cm}^{-1}$ in IR spectra and around 1056, 908 and $834 \mathrm{~cm}^{-1}$ in the Raman spectra. Creatine was detected in eight of ten analyzed epileptic samples and in only one of six controls under the study. The number of deposits in epileptic animals varied from 1 to 100 and a relative majority of inclusions were detected in the area of the Dentate Gyrus and in the multiform hippocampal layer. Moreover, the number of creatine inclusions was positively correlated with the total time of seizure activity.

Keywords Pilocarpine-induced epilepsy · Creatine deposits · SRFTIR microspectroscopy and imaging · Raman microspectroscopy

\section{Introduction}

Epilepsy is one of the most frequently occurring neurological diseases. It is characterized by recurrent spontaneous seizures leading, without an appropriate therapeutic treatment, to severe cognitive and social impairments [1-4]. Changes underlying these impairments include seizureinduced variations in tissue levels of glutamate or GABA (gamma-aminobutyric acid), excessive activation of glutamate receptors, oxidative stress, overexpression of cytokines and finally apoptosis or necrosis of nerve cells $[5,6]$. Despite the intensive investigations, the mechanisms underlying the mentioned abnormalities still remain poorly understood.

Animal models of epilepsy are valuable tools to study the pathogenesis of this disease and to evaluate potential antiepileptic drugs [7, 8]. Chronic models of acquired (symptomatic) epilepsy include those in which epilepsy- 
like conditions are evoked by electrical (kindling model) or pharmacological stimuli (for example, pilocarpine and kainate models) in previously healthy animals, mostly rats [7]. In the most frequently used model of temporal lobe epilepsy, following the pilocarpine-induced seizures, numerous brain structures which are involved in the epileptiform activity may display different degrees of neurodegeneration, depending on the seizure intensity and duration. The neurodegenerative changes are particularly located in the sectors 1 and 3 of the Ammon's horn (CA1 and CA3, respectively) [9] and among the processes suspected of leading to hippocampal anomalies, oxidative stress accompanying mitochondrial dysfunction is mainly taken into account [10].

In our previous studies, we analyzed the biochemical changes occurring in the CA3 sector and dentate gyrus (DG) of the rat hippocampal formation in the acute period after pilocarpine injection [11]. In animals suffering from seizures, we observed changes in the secondary structure of proteins (from $\alpha$-helical to $\beta$-sheet) and the saturation level of phospholipids. The mentioned abnormalities were detected in the pyramidal cell layer of CA3 and in the multiform and molecular layers of DG area.

Carrying out the measurements using SRFTIR microspectroscopy, crystalline inclusions of unknown origin were noticed within hippocampal formation from epileptic animals. The preliminary analysis done during this experiment suggested that the mentioned deposits included creatine. Because similar creatine inclusions have been previously observed in the hippocampus of amyloid precursor protein transgenic mice as well as in the autopsy samples from people deceased with Alzheimer's disease or amyotrophic lateral sclerosis [12-15], we decided to continue our study and verify the possible role of creatine in the pathogenesis and progress of pilocarpine-evoked seizures and seizure-induced neurodegenerative changes.

Brain, constituting only $2 \%$ of body mass, consumes almost $20 \%$ of total body energy requirements [16]. The most energy used in the nervous system is provided in the form of ATP by mitochondria [17]. Creatine, being a nitrogenous organic amino acid, plays important roles in this process. Creatine is an element of the brain creatine/ phosphocreatine/creatine kinase $(\mathrm{Cr} / \mathrm{PCr} / \mathrm{CK})$ system which serves as a temporal and spatial energy buffer [18]. However, the energy storage and a high-energy phosphate shuttle from mitochondria to the cytoplasmic places of consumption are not the only functions of creatine. It can also play a role in protein synthesis and in its phosphorylated form in membrane stabilization [19, 20]. Additionally, the studies of Almeida et al. showed that creatine had also to be considered as a neuromodulator or co-transmitter which was able to modify the activity of some postsynaptic receptors [21].
The key significance of creatine for the energetic metabolism and its other functions in the CNS have been evidenced by creatine deficiency syndromes resulting from inborn errors of creatine synthesis or transport. Patients suffering from them present clinical features including severe mental retardation, movement disorders, autism, and epilepsy [22, 23].

Troubles in CNS energy metabolism of different origin play critical roles in the progression of neurological diseases as a primary or secondary mechanism in neuronal death cascade. Therefore, the therapeutic potential of creatine for brain pathologies has recently been tested using animal models of neurodegenerative disorders, such as Parkinson's disease, Huntington's disease or amyotrophic lateral sclerosis [24-28]. In Parkinson's disease, the treatment with creatine resulted in a significant protection against both CNS dopamine depletion and neuronal loss in the substantia nigra [24]. In an animal model of Huntington's disease, creatine supplementation increased animals' life span, decreased their brain atrophy and delayed the formation of mutant huntingtin aggregates [25]. For these two diseases also ongoing clinical trials seem to be very promising in contrast to amyotrophic lateral sclerosis for which subsequent clinical tests did not confirm efficacy of the treatment with the creatine [29-31].

In the present paper, two measurement techniques, i.e., SRFTIR and Raman microspectroscopy were used to examine the possible role of creatine in the process of epileptogenesis. Analysis of vibrational modes of molecules allowed us to detect creatine deposits within rat nervous tissue and to compare the frequencies of their occurrence in the postepileptic and control hippocampal formations. Additionally, correlations between the numbers of creatine inclusions and the animal seizure behavior parameters within the 6-h period after pilocarpine injection were calculated.

\section{Materials and methods}

\section{Animals}

All animal-use procedures were approved by the Bioethical Commission of the Jagiellonian University in accordance with international standards. Adult male Wistar rats were obtained from an animal colony of the Institute of Pediatrics, Collegium Medicum, Jagiellonian University, Krakow and maintained under conditions of controlled temperature $\left(20 \pm 2{ }^{\circ} \mathrm{C}\right)$ and illumination (12-h light:12$\mathrm{h}$ dark cycle). A solid diet (Labofeed) and water were available ad libitum.

Epilepsy induction and behavioral observations

The cholinergic agonist, pilocarpine, was used in order to induce seizures in rats. Pilocarpine was injected intra- 
peritoneally (300 mg/kg, Sigma P6503) on the postnatal day 60. Scopolamine methyl bromide $(1 \mathrm{mg} / \mathrm{kg}$, Sigma S8502) was injected i.p. $30 \mathrm{~min}$ prior to pilocarpine to reduce its peripheral effects. After pilocarpine injection, the rats were continuously observed during the 6-h period. Motor symptoms were rated on the six-point scale used in our previous studies [32]. Additionally, the observations provided the data on general parameters of the status epilepticus such as: (1) the latency of the first motor sign, (2) the time when it occurred within the 6-h observation period, and (3) the time when the acute period ended. Ten epileptic animals were used in this study, four with intermediate and six with heavy seizures. The latency of the first motor signs varied from 10 to $20 \mathrm{~min}$, while the duration of seizure activity within the observation period varied from 180 to $350 \mathrm{~min}$.

\section{Sample preparation}

After 6-h observation of the animals' behavior, the rats were perfused with physiological saline solution of high analytical purity. The skulls were opened, and the brains were excised and deeply frozen in liquid nitrogen. Afterwards, they were cut with a cryomicrotome into 10$\mu \mathrm{m}$ thick sections. The sections containing the dorsal part of the hippocampal formation were placed on MirrIR low-e microscopic slides and stored at $-70^{\circ} \mathrm{C}$. The presence of creatine deposits was examined in the hippocampal tissue of ten epileptic and six control animals.

\section{Data acquisition}

The measurements of tissue samples were carried out in February 2010 at the SMIS beamline of SOLEIL synchrotron (Saint Aubin, France). SRFTIR microspectroscopy was the main analytical technique used in the investigation. The measurements were carried out in transflection mode using a Continuum XL infrared microscope equipped with a $50 \mu \mathrm{m}$ MCT detector and coupled to an FTIR ThermoNicolet 5700 spectrometer. The beam size was reduced to $10 \times$ $10 \mu \mathrm{m}^{2}$ using a double pass aperture to eliminate diffraction and a $32 \times$ NA 0.6 infinity corrected Schwarzschild objective. Infrared spectra were recorded between 650 and $4000 \mathrm{~cm}^{-1}$ by co-adding 64 scans for each individual sample spectrum at a nominal physical resolution of $6 \mathrm{~cm}^{-1}$. Spectra were collected and analyzed using the data acquisition software OMNIC (Version 8.0).

Raman microspectroscopy was used as an additional complementary measurement technique. The main goal of its application was to confirm the results obtained using SRFTIR microspectroscopy and to verify whether the observed creatine deposits were localized within the analyzed tissue and were not laboratory contaminants.
All Raman measurements were recorded using a DXR Raman microscope (ThermoNicolet) equipped with a $780 \mathrm{~nm}$ ThermoNicolet laser providing $14 \mathrm{~mW}$ of power on sample, edge filters, a charge coupled device detector and a $100 \times / 0.9$ numerical aperture objective giving a spot size of $0.9 \mu \mathrm{m}$ at $780 \mathrm{~nm}$. The spectra were recorded with one accumulation of $80 \mathrm{~s}$ from 50 to $3400 \mathrm{~cm}^{-1}$. The microspectrometer was operated in non-confocal mode with a pinhole of $50 \mu \mathrm{m}$ and a 400 lines $/ \mathrm{mm}$ grating, giving a spectral resolution varying from 10.1 to $18.5 \mathrm{~cm}^{-1}$. For depth profiles, vertical steps of $2 \mu \mathrm{m}$ were performed through around $10 \mu \mathrm{m}$ thick sample, and $2.5 \mu \mathrm{m}$ steps were used for horizontal maps in the plan of the section.

The only pre-treatment performed on IR and Raman spectra was baseline correction. The mentioned procedure was used only in case of comparisons of the spectra from hippocampal inclusions, normal tissue and creatine (see Figs. 1 and 4). Chemical mapping of selected IR or Raman bands was done based on their areas after baseline subtraction. In this case, no preprocessing was performed on the spectral data.

\section{Results}

\section{SRFTIR microspectroscopy study}

The detailed microscopic observations of tissue slices including the hippocampal formation of epileptic animals showed the presence of quite a large number of inclusions of unknown origin. The preliminary measurements done in 2008 at SMIS beamline of SOLEIL suggested the presence of creatine in the mentioned deposits. Therefore, we decided to use two complementary measurement techniques, namely SRFTIR and Raman microspectroscopies in order to examine the possible role of creatine in the pathogenesis and progress of pilocarpine-induced epileptic seizures. For this purpose, the point IR maps were recorded for all the inclusions found within the area of the hippocampal formation in ten epileptic and six control samples.

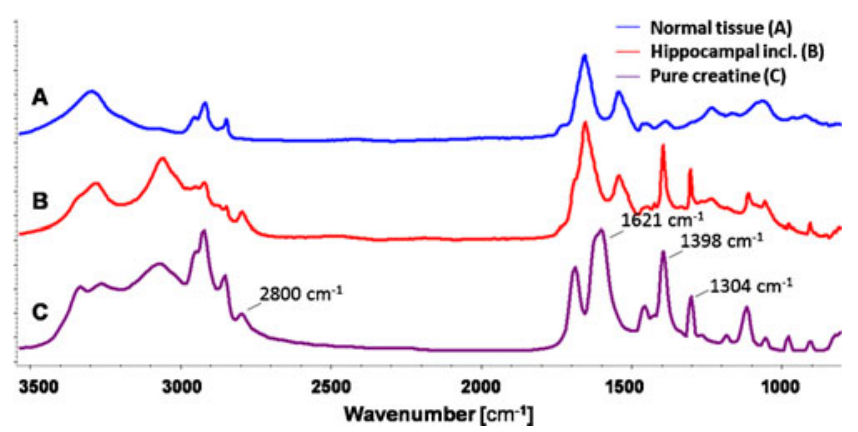

Fig. 1 The comparison of baseline corrected IR absorption spectra recorded for the analyzed hippocampal inclusion $(\mathbf{B})$, pure creatine (C) and normal hippocampal tissue (A) 
Fig. 2 Chemical maps obtained for CA3 hippocampal area presenting the distributions of creatine absorption bands $(\sim 1398$ and $\sim 1304 \mathrm{~cm}^{-1}$ ) in comparison with the distributions of bands specific for the absorption of lipids $\left(2921 \mathrm{~cm}^{-1}\right)$ and compounds containing phosphate groups $(\sim 1225$ and $\left.\sim 1080 \mathrm{~cm}^{-1}\right)$. The images were generated from the baselinesubtracted areas of the analyzed absorption bands. The hippocampal inclusions were marked with arrows
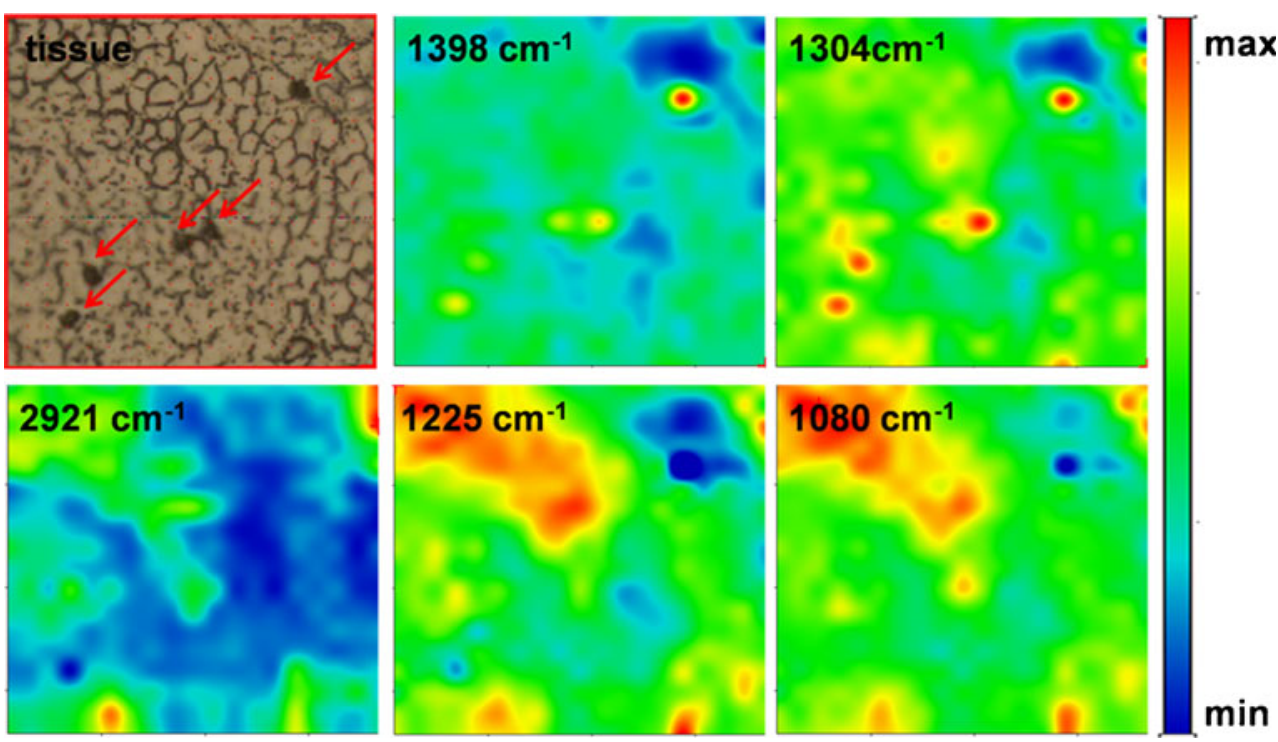

In Fig. 1, a typical spectrum of the analyzed hippocampal inclusion was compared with that from normal nervous tissue and with the spectrum of pure creatine.

The presence of creatine in the examined inclusions was confirmed based on the IR absorption bands characteristic for this compound and occurring at the wavenumbers around 2800, 1621, 1398, and $1304 \mathrm{~cm}^{-1}$ [15]. Additionally, in order to exclude the presence of phosphocreatine within the deposits, for some of them two dimensional IR imaging was done and the obtained distributions of intensities of creatine bands were compared with chemical maps obtained for the absorption bands specific for the compounds containing phosphate group(s). In Fig. 2, the results of such chemical mapping carried out for inclusions from the selected CA3 epileptic area were presented. Similar maps recorded for epileptic DG area were presented in Electronic Supplementary Material Figure S1.

As one can notice from Fig. 2, a higher absorption of IR radiation at 1398 and $1304 \mathrm{~cm}^{-1}$ and lower at 1225 and $1080 \mathrm{~cm}^{-1}$ was correlated with the positions of inclusions what suggested that they contained creatine but not phosphocreatine.

From among six control samples only one contained creatine inclusions (25 inclusions mostly at multiform layer). In case of epileptic group, creatine aggregates were observed in eight of ten animals under investigation and the number of inclusions varied from 1 to 100 .
In order to verify if the localization of creatine deposits is characteristic for specific cellular layers or regions of hippocampal formation the mean and median values of their number in the compared areas were calculated for epileptic group (eight epileptic animals in which creatine deposits were observed). The number of creatine inclusions in the pyramidal (pyr), granular (gran), multiform (mult), and molecular (mol) layers as well as in the areas of DG, hilus of DG, CA3, and CA1-CA2 were presented in Table 1 and Fig. 3.

As one can notice from Table 1 and Fig. 3, a relative majority of creatine inclusions was localized in the multiform layer and in the area of DG.

The further step of the investigation was to analyze correlations between the number of inclusions in the analyzed areas and the quantitative parameters describing the seizure behaviors induced by pilocarpine injection. The following behavioral parameters were taken into account: the latency of the first motor signs (T1), the maximal intensity of seizures (MAX) and the duration of the acute period $(T)$. Spearman's rank correlation coefficients $\left(r_{\mathrm{s}}\right)$ were used as a measure of strength of the dependence between the number of creatine inclusions and the behavioral parameters. The values of Spearman's rank correlation coefficients calculated for the examined cellular layers and areas of the hippocampal formation were presented in Table 2.

Taking into account the number of the analyzed samples the Spearman's rank correlation coefficient was treated as
Table 1 The median and average values of the number of creatine inclusions in specific cellular layers and hippocampal regions in epileptic samples

\begin{tabular}{|c|c|c|c|c|c|c|c|c|c|}
\hline & \multicolumn{4}{|c|}{ Cellular layer } & \multicolumn{4}{|c|}{ Region } & \multirow[t]{2}{*}{ Total } \\
\hline & pyr & gran & mult & mol & DG & $\mathrm{H}$ & CA3 & CA1-CA2 & \\
\hline Median & 2 & 1 & 8 & 7 & 4 & 2 & 0 & 4 & 21 \\
\hline Average & 7 & 7 & 14 & 9 & 12 & 6 & 6 & 12 & 35 \\
\hline SD & 3 & 3 & 6 & 3 & 5 & 3 & 3 & 5 & 15 \\
\hline
\end{tabular}



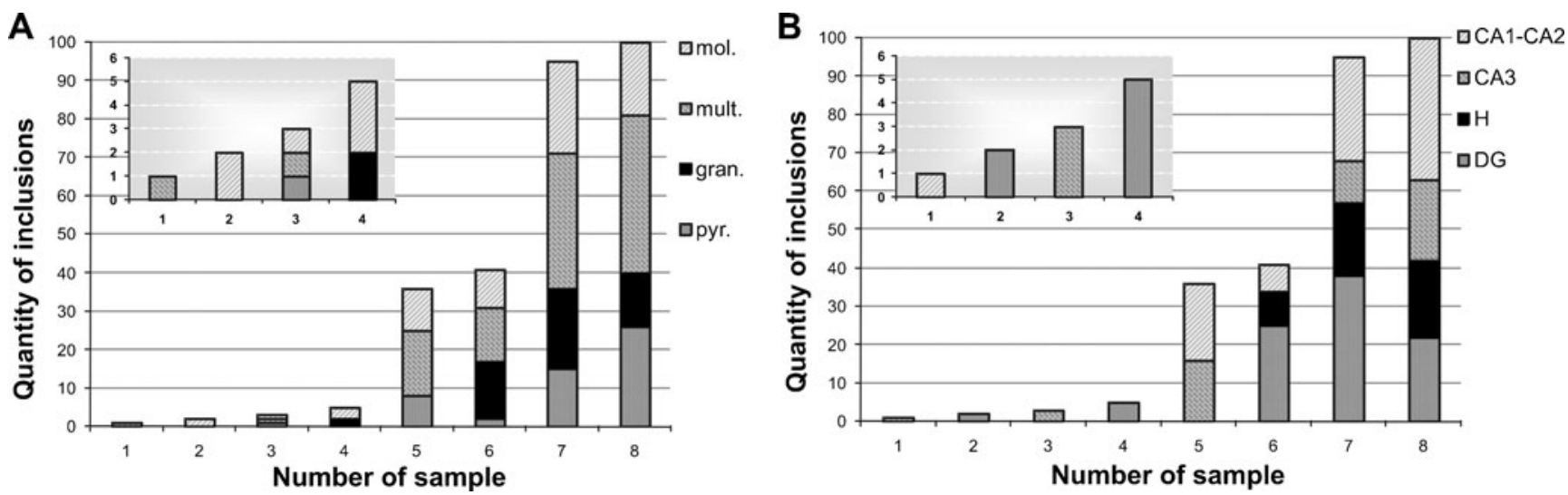

Fig. 3 The number of creatine inclusions in specific cellular layers (A) and areas (B) of the hippocampal formation in eight epileptic samples with creatine deposits. The data for samples 1-4 were magnified in insets

significant when its absolute value was $\geq 0.7$ and the values fulfilling this condition were marked. The following correlations were observed between the number of creatine deposits and the parameters describing rat behavior in the acute period of status epilepticus:

- The quantity of creatine inclusions in granular $\left(r_{\mathrm{s}}=\right.$ $0.76, p<0.05)$ and molecular $\left(r_{\mathrm{s}}=0.80, p<0.05\right)$ layers was positively correlated with the total time of epileptic activity;

- Similar relation was observed for the DG $\left(r_{\mathrm{s}}=0.85\right.$, $p<0.05)$ and for the whole hippocampal formation $\left(r_{\mathrm{s}}=0.74, p<0.05\right)$;

- The negative, statistically significant correlation, but with the absolute value of Spearman's rank correlation coefficient less than $0.7,\left(r_{\mathrm{s}}=-0.61, p<0.05\right)$ was found between the number of deposits in DG and the latency of the first motor signs.

In the next step of the analysis, the epileptic animals were divided into two groups: rats with intermediate (MAX $=1.5$ or 2 ) and heavy seizures $(\mathrm{MAX}=2.5$ or 3 ). The first group included four whilst the second six animals. For both groups the medians of the number of creatine inclusions in specific cellular layers/areas were evaluated and the differences between them were tested using the $U$ Mann-Whitney test. The mentioned statistical test did not confirm the existence of a significant difference in the number of deposits between the animals with intermediate and heavy seizures.
Raman microspectroscopy study

The results obtained using Raman spectroscopy evidently confirmed that the inclusions observed previously using SRFTIR microspectroscopy consisted of creatine. In Fig. 4, the Raman spectra recorded for normal nervous tissue, hippocampal inclusion and pure creatine were compared. The sharp shape of the bands present in the spectrum (B) may suggest the crystalline nature of the deposit.

In order to verify if creatine inclusions were present within the nervous tissue and were not laboratory contaminants on tissue surface, the line or 2D Raman depth profiles were recorded. As an example, one of them was presented in Fig. 5. Based on such measurements, we were able to confirm that creatine was located within the nervous tissue and the vertical size of the deposits varied between a few to around $20 \mu \mathrm{m}$.

\section{Discussion and conclusions}

The main goal of this study was to identify creatine deposits and to analyze their frequency in the hippocampal tissue in rats with pilocarpine-induced seizures and in naive controls. To achieve these goals, two complementary measurement techniques, allowing for analysis of vibrational modes of molecules, SRFTIR and Raman microspectroscopy, were used. The presence of creatine in the investigated inclusions was confirmed based on the
Table 2 The values of Spearman's rank correlation coefficients for the examined cellular layers and regions of the hippocampal formation

\begin{tabular}{|c|c|c|c|c|c|c|c|c|c|}
\hline & \multicolumn{4}{|c|}{ Cellular layer } & \multicolumn{4}{|c|}{ Region } & \multirow[t]{2}{*}{ Total } \\
\hline & pyr & gran & mult & mol & DG & $\mathrm{H}$ & CA3 & CA1-CA2 & \\
\hline $\mathrm{T} 1$ & -0.20 & -0.51 & -0.04 & -0.35 & -0.61 & -0.42 & -0.04 & 0.04 & -0.38 \\
\hline MAX & -0.18 & 0.38 & -0.08 & -0.09 & 0.26 & 0.07 & -0.40 & -0.05 & -0.02 \\
\hline $\mathrm{T}$ & 0.44 & 0.76 & 0.30 & 0.80 & 0.85 & 0.53 & 0.27 & 0.32 & 0.74 \\
\hline
\end{tabular}




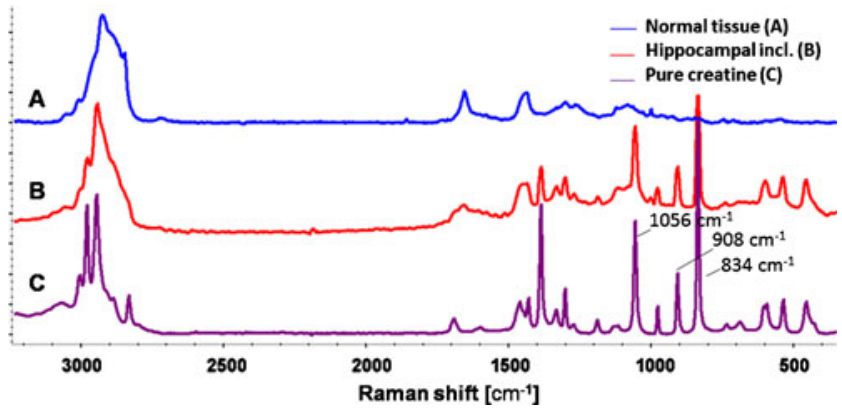

Fig. 4 The comparison of baseline corrected Raman spectra recorded for the analyzed hippocampal inclusion $(\mathbf{B})$, pure creatine $(\mathbf{C})$ and normal hippocampal tissue (A)

occurrence of the bands specific for the analyzed compound in the vibrational spectra. For IR absorption spectra, these were the bands occurring at the wavenumbers around 2800 , 1621,1398 , and $1304 \mathrm{~cm}^{-1}$. In turn, in Raman spectra the bands around 1056, 908, and $834 \mathrm{~cm}^{-1}$ were mainly taken into account [12].
Our results showed that the frequency of creatine deposits was significantly higher in the animals with pilocarpine-induced seizures than in the control group. Creatine inclusions were detected in only one of six control animals while the presence of creatine was confirmed for $80 \%$ of epileptic animals. Thus, we can expect that the presence of creatine deposits may be an effect of pathological conditions occurring in the brain during the acute phase of status epilepticus.

During epileptic seizures there is an increased energy demand, and $\mathrm{Cr} / \mathrm{PCr} / \mathrm{CK}$ system may play a pivotal role in providing the energy necessary for seizure progression [33]. The presence of creatine deposits in epileptic animals may suggest a disturbed function of mitochondrial creatine kinase (CK) catalyzing creatine phosphorylation. Such a conclusion is very probable, taking into account the fact that reactive oxygen species can inactivate mitochondrial $\mathrm{CK}$, by changing its octameric conformation into an inactivated dimeric form [21] and the data concerning an excessive free radical formation and lipid peroxidation
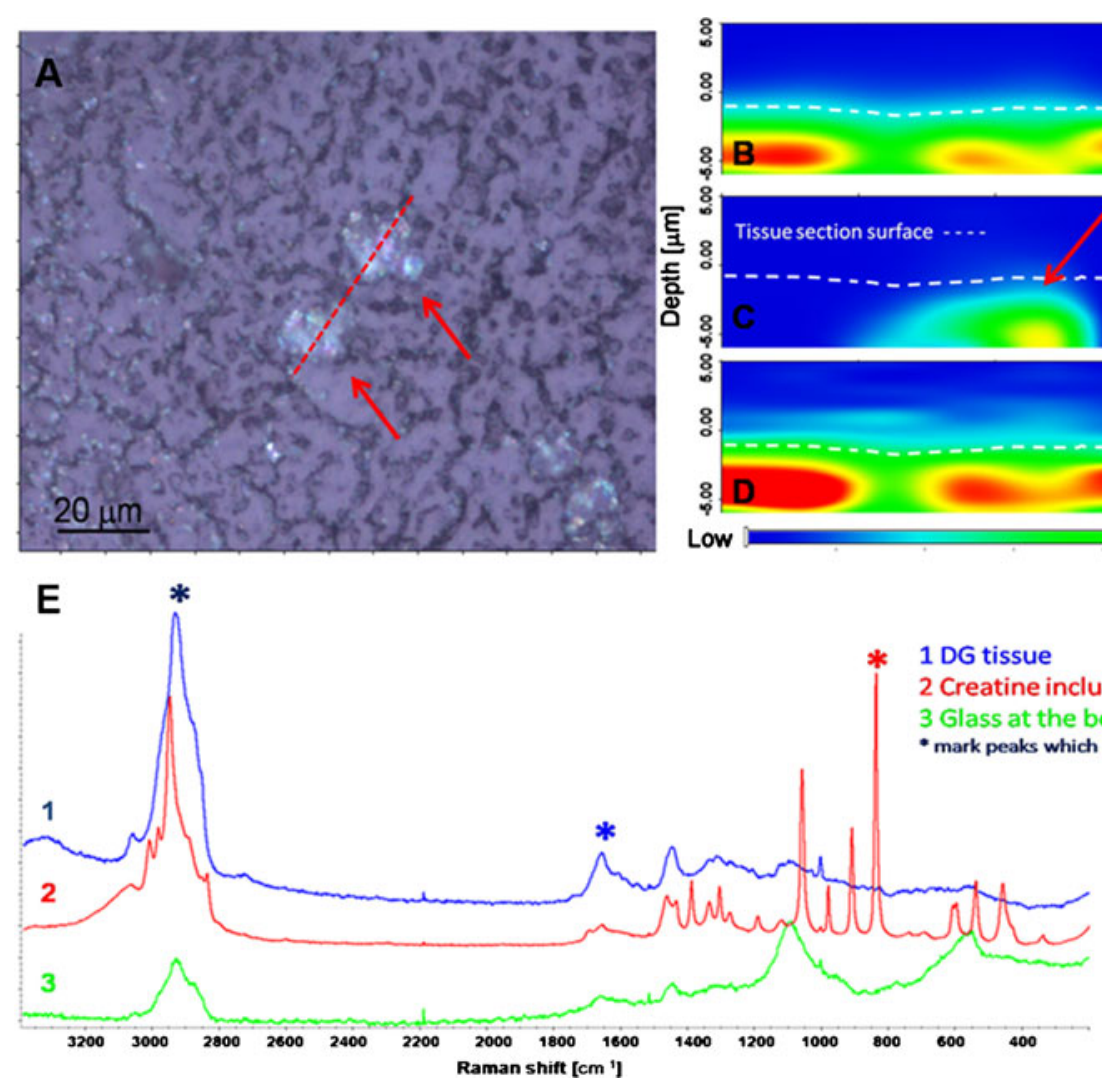

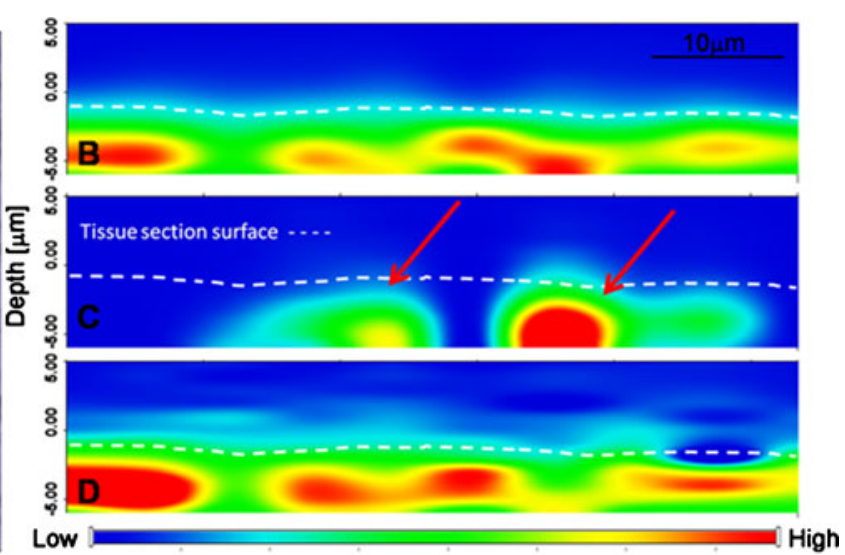

from the area of the $850-815 \mathrm{~cm}^{-1}$ band from creatine showing that the two inclusions are integrated within the nervous tissue. D Spectral image generated from the area of the amide I band from proteins. The surface of the section appears more fuzzy in this wavelength range (6$7 \mu \mathrm{m})$. E Spectra extracted from the map: normal tissue (blue), hippocampal inclusion (red) and glass beneath the tissue (green). The bands used to generate the spectral images are marked by stars 
observed in different brain areas during status epilepticus induced by pilocarpine and in the lithium-pilocarpine model [34-38]. In agreement with such thesis are also our previous results showing an increased lipid saturation (a marker of excessive oxidative stress) and conformational changes of proteins in the DG and CA3 hippocampal areas from animals treated with pilocarpine [11].

On the other hand, the study of Almeida et al. [21] showed that creatine was released from central neurons in a manner typical of classical neurotransmitters - upon depolarization of brain tissue depending on the level of extracellular $\mathrm{Ca}^{2+}$ ions and involving activation of voltage-dependent $\mathrm{Na}^{+}$and $\mathrm{K}^{+}$channels. The level of electrically evoked creatine release was diminished in the absence of extracellular $\mathrm{Ca}^{2+}$. On the other hand, the blockade of action-potential with an $\mathrm{Na}^{+}$channel inhibitor reduced, whereas the blockade of $\mathrm{K}^{+}$channels enhanced its electrically stimulated release [21]. Taking into account the results of Almeida et al. and the conditions occurring in the nerve cells during excessive discharges, we conclude that the increased frequency of creatine inclusions may also be connected with its neuromodulatory role.

For many years, cerebral creatine was believed to be principally of peripheral origin [39], but the works of Braissant et al. showed that glycineamidinotransferase and guanidinoacetate methyltransferase, two enzymes necessary for creatine synthesis and function, were also expressed in the brain and, therefore, the brain was shown to be capable of its own creatine synthesis [40, 41]. However, in spite of brain synthesis of creatine, according to Tachikawa et al. [42], the brain barriers might be key determinants of the levels of guanidine compounds, including creatine, in the brain and cerebrospinal fluid. Since, changes in the bloodbrain barrier permeability may be a common outcome of single and repeated seizures, the other possible explanation for the increased presence of creatine deposits in the epileptic brain may be seizure-induced blood-brain barrier damage resulting in its increased permeability for peripheral creatine [43].

\section{Conclusions}

In the present work, SRFTIR and Raman microspectroscopies were used to confirm the presence of creatine in inclusions localized within the hippocampal tissue from rats with pilocarpine-induced seizures. The comparison of epileptic and control rats showed for the first time an increased frequency of creatine inclusions in the epileptic animals. Additionally, the number of inclusions detected in the epileptic animals was positively correlated with the total time of seizure activity within the 6-h observation period. The obtained results may suggest seizure-induced disrup- tion of creatine kinase function, impairment of neuromodulatory function of creatine or increased permeability of the blood-brain barrier for creatine from periphery.

Acknowledgments This work was supported by Polish Ministry of Science and Higher Education and the following grants:

1. The European Community-Research Infrastructure Action under FP6 "Structuring the European Research Area" Programme (through the Integrated Infrastructure Initiative "Integrating Activity on Synchrotron and Free Electron Laser Science").

2. SOLEIL experimental grants: 20060063 and 20090749.

3. The Ministry of Science and Higher Education grants K/ZDS/ 001956/2011 and IUVENTUS PLUS n. JP2010005370.

4. The research leading to these results has received funding from the European Community's Seventh Framework Programme (FP7/ 2007-2013) under grant agreement n. 226716.

5. The first author is also grateful for the support from the Foundation for Polish Science (START Programme).

Open Access This article is distributed under the terms of the Creative Commons Attribution Noncommercial License which permits any noncommercial use, distribution, and reproduction in any medium, provided the original author(s) and source are credited.

\section{References}

1. Chang BS, Lowenstein DH (2003) N Engl J Med 349:1257-1266

2. Karanassios V (2004) Spectroc Acta Pt B-Atom Spectr 59:909-928

3. Karanassios V, Johnson K, Smith AT (2007) Anal Bioanal Chem 388:1595-1604

4. Engel J, Pedley TA (2008) Epilepsy: a comprehensive textbook. Lippincott, Williams \&Wilkins, Philadelphia

5. Haut SR, Veliskova J, Moshe SL (2004) Lancet Neurol 3:608-617

6. Fujikawa DG (2005) Epilepsy Behav 7:3-11

7. Loscher W (2002) Epilepsy Res 50:105-123

8. Sharma AK, Reams RY, Jordan WH, Miller MA, Thacker HL, Snyder PW (2007) Toxicol Pathol 35:984-999

9. Wasterlain CG, Fujikawa DG, Penix L, Sankar R (1993) Epilepsia 34:37-53

10. Patel M (2004) Free Radic Biol Med 37:1951-1962

11. Chwiej J, Dulinska J, Janeczko K, Dumas P, Eichert D, Dudala J, Setkowicz Z (2010) J Chem Neuroanat 40:140-147

12. Gallant M, Rak M, Szeghalmi A, Del Bigio MR, Westaway D, Yang J, Julian R, Gough KM (2006) J Biol Chem 281:5-8

13. Burklen TS, Schlattner U, Homayouni R, Gough K, Rak M, Szeghalmi A, Wallimann T (2006) J Biomed Biotech 2006:1-11

14. Kastyak MZ, Szczerbowska-Boruchowska M, Adamek D, Tomik B, Lankosz M, Gough KM (2010) Neuroscience 166:1119-1128

15. Szczerbowska-Boruchowska M, Chwiej J, Dumas P, Tomik B, Adamek D, Lankosz M (2010) Spectrosc Eur 22:17-20

16. Shulman RG, Rothman DL, Behar KL (2004) Hyder F 27:489-495

17. Wong-Riley MT (1989) Trends Neurosci 12:94-101

18. Bessman SP, Carpenter CL (1985) Ann Rev Biochem 54:831-862

19. Sipila I, Rapola J, Simell O, Vannas A (1981) N Engl J Med 304:867-870

20. Sharov VG, Saks VA, Kupriyanov VV, Lakomkin VL, Kapelko VI, Steinschneider AYa, Javadov SA (1987) J Thorac Cardiovasc Surg 94:749-761

21. Almeida LS, Salomons GS, Hogenboom F, Jakobs C, Schoffelmeer AN (2006) Synapse 60:118-123

22. Béard E, Braissant O (2010) J Neurochem 115:297-313

23. Nasrallah F, Feki M, Kaabachi N (2010) Pediatr Neurol 42:163-171 
24. Matthews RT, Ferrante RJ, Klivenyi P, Yang L, Klein AM, Mueller G, Kaddurah-Daouk R, Beal MF (1999) Exp Neurol 157:142-149

25. Ferrante RJ, Andreassen OA, Jenkins BG, Dedeoglu A, Kuemmerle S, Kubilus JK, Kaddurah-Daouk R, Hersch SM, Beal MF (2000) J Neurosci 20:4389-4397

26. Ellis AC, Rosenfeld J (2004) CNS Drugs 18:967-980

27. Klivenyi P, Kiaei M, Gardian G, Calingasan NY, Beal MF (2004) J Neurochem 88:576-582

28. Zhang W, Narayanan M, Friedlander RM (2003) Ann Neurol 53:267-270

29. Adhihetty PJ, Beal MF (2008) Neuromol Med 10:275-290

30. Shefner JM, Cudkowicz ME, Schoenfeld D, Conrad T, Taft J, Chilton M, Urbinelli L, Qureshi M, Zhang H, Pestronk A, Caress J, Donofrio P, Sorenson E, Bradley W, Lomen-Hoerth C, Pioro E, Rezania K, Ross M, Pascuzzi R, Heiman-Patterson T, Tandan R, Mitsumoto H, Rothstein J, Smith-Palmer T, MacDonald D, Burke D (2004) Neurology 63:1656-1661

31. Rosenfeld J, King RM, Jackson CE, Bedlack RS, Barohn RJ, Dick A, Phillips LH, Chapin J, Gelinas DF, Lou JS (2008) Amyotroph Lateral Scler 9:266-272
32. Setkowicz Z, Ciarach M, Guzik R, Janeczko K (2004) Epilepsy Res 61:63-72

33. Kim DW, Yeo SI, Ryu HJ, Kim JE, Song HK, Kwon OS, Choi SY, Kang TC (2010) BMC Neurosci 11:141

34. Freitas RM, Souza FCF, Vasconcelos SMM, Viana GSB, Fonteles MMF (2005) FEBS J 272:1307-1312

35. Freitas RM (2009) Neurosci Lett 462:225-229

36. Tejada S, Roca C, Sureda A, Rial RV, Gamundí A, Esteban S (2006) Brain Res Bull 69:587-592

37. Tejada S, Sureda A, Roca C, Gamundi A, Esteban S (2007) Brain Res Bull 71:372-375

38. Peternel S, Pilipović K, Župan G (2009) Prog Neuropsychopharmacol Biol Psychiat 33:456-462

39. Wyss M, Kaddurah-Daouk R (2000) Physiol Rev 80:11071213

40. Braissant O, Henry H, Loup M, Eilers B, Bachmann C (2001) Mol Brain Res 86:193-201

41. Braissant O, Henry H, Villard AM, Speer O, Wallimann T, Bachmann C (2005) BMC Dev Biol 5:9

42. Tachikawa M (2011) Hosoya K 8:13

43. Sahin D, Ilbay G, Ates N (2003) Pharmacol Res 48:69-73 